\title{
ANTIISCHEMIC PROPERTIES OF THE NEW ANTIOXIDANT DRUG VALEOKOR-Q10 (EXPERIMENTAL STUDY)
}

\author{
(C) Selezneva A. I. ${ }^{2}$, Makarov V. G. ${ }^{1}$, Djachuk G. I. ${ }^{2}$, Makarova M. N. ${ }^{1}$, \\ Zabozlaev A. A. ${ }^{3}$, Khodko S. V. ${ }^{1}$, Kovaleva M. A. ${ }^{1}$
}

'Saint-Petersburg Institute of Pharmacy, Russia

${ }^{2}$ Northwestern State Medical University n. a. I. I. Mechnikov, Saint-Petersburg, Russia

${ }^{3}$ NPK "PHARMASOFT", Moscow, Russia

The aim was an experimental study of antiischemic effect of the new antioxidant drug Valeokor-Q10 on the model of acute myocardial infarction. Acute experimental myocardial infarction was modulated by the method of $\mathrm{H}$. Selye (1960) - occlusion of the descending branch of left coronary artery in Wistar rats. The drug ValeokorQ10 was administered in forms of injection at doses of $1,6,2,5,7,4,22,2 \mathrm{mg} / \mathrm{kg}$ intravenously, and suspension of the tablets at doses of $0,2,1,6,7,4 \mathrm{mg} / \mathrm{kg}$ intraperitoneally. Mildronate (JSC Grindeks, Latvia) was used as reference. The amplitude of the ST complex on the ECG, enzymes aspartate aminotransferase and creatine kinase and neovascularization of damaged myocardium were controlled. Positive effect of Valeokor-Q10 on the dynamics of the complex amplitude of the ST on ECG was observed. Valeokor-Q10 at a dose of $1,6 \mathrm{mg} / \mathrm{kg}$ introperitoneally and doses of $1,6,2,5 \mathrm{mg} / \mathrm{kg}$ intravenously reduced activity of creatine kinase. Intraperitoneal administration of Valeokor-Q10 in doses of 1,6 and $7,4 \mathrm{mg} / \mathrm{kg}$ reduced the level of aspartate aminotransferase. The drug increased the neovascularization of ischemic myocardium area and accelerated differentiation of blood vessels in arterioles and venules. The maximum effect was observed at a dose of $1,6 \mathrm{mg} / \mathrm{kg}$. New drug has antiischemic effect and can be successfully used in the treatment of coronary heart disease.

\section{DEVELOPMENT AND VALIDATION OF TLC METHOD FOR THE IDENTIFICATION OF AERVA LANATA HERB}

\section{○) Semionova M.V., Obukhova V. V., Kuzminova L.V.}

\section{JSC "Krasnogorskleksredstva”, Krasnogorsk, Moscow region, Russia}

In order to ensure quality and efficacy of herbal medicinal products the national quality standards must contain the modern quality control methods. The purpose of our study was to develop and validate the identification method for Aerva lanata herb. The study object was Aerva lanata herb; TLC was chosen as an analytical method for identification of phenolic compounds profile in the samples. Ethanol (80\%) appeared to be the best extraction agent and the best Aerva lanata herb phenolic compounds resolution was achieved using mobile phase ethyl acetate - anhydrous formic acid - water (12:2.5:3) in the plates TLC Silica gel 60 F254 (aluminium sheets, Merck, Germany). Solutions of rutin and quercetin were used as reference solutions. After developing the plate was heated at $100-105^{\circ} \mathrm{C}$ for 3-5 minutes. Then the plate was sequentially sprayed with $1 \%$ diphenylboryloxyethylamin solution and $5 \%$ polyethyleneglycol solution (both in $96 \%$ ethanol) and dried at room temperature for 30 minutes. The following zones of reference compounds present: detection at $365 \mathrm{~nm}$ with the reference solutions: the zone with yellow, yelloworange or orange color $\left(R_{f}\right.$ approx. $0.4-0.5$ that was accepted as $R_{s}=1.0$, due to rutin) and the zone with yellow, yellow-orange or orange color $\left(R_{s}\right.$ approx. 1.9-2.5, due to quercetin).

The following zones of phenolic compounds present in the plate with the test solution: the zone with yellow, green-yellow, yellow-orange or orange color $\left(R_{s}\right.$ (by rutin) approx. 0.3-0.4), 2 zones with green or green-yellow color $\left(R_{s}\right.$ approx. $0.4-0.5$ and $\left.1.8-2.2\right)$, the zone with light blue color $\left(\mathrm{R}_{\mathrm{s}}\right.$ approx. 0.8-1.0); others zones could be present. The method validation was performed on 6 industrial batches (from 2009 to 2012 production years) by workers of 2 laboratories (Research \& Development Department and Quality Control Department). The method specificity was evaluated by coincidence of the different batches chromatographic profiles by the main zones and by compliance of abovementioned profiles with the test solution chromatogram description. Chromatographic profiles of the different batches have coincided and been compliant with the test solution chromatogram description. The resolution between zones of rutin ( $R_{s}$ approx. 1.0) and quercetin $\left(R_{s}\right.$ approx. 1.9-2.5) in the chromatogram obtained with the reference solutions has been chosen as a chromatographic system suitability index. The resolution value between the 
chosen zones must not be less than 10 . The resolution values that had been calculated by the chromatograms obtained in different laboratories satisfied the method requirements. The suggested method can be used for identification of Aerva lanata herb in routine analyses. This method has been included into the draft version of "Krasnogorskleksredstva" House monograph on Aerva lanata herb.

\section{NEUROPROTECTIVE EFFECTS OF CORTEXIN, A DRUG DERIVED FROM THE BRAIN CORTEX}

\section{() Shabanov Petr D.}

Military Medical Academy, 6, Acad. Lebedev street, St.Petersburg, 194044, Russia Institute of Experimental Medicine NWB RAMS, 12, Acad. Pavlov street, St.Petersburg, 197376, Russia; e-mail: pdshabanov@mail.ru

According to the conception of neuroprotection widely spreaded in neurology, neuroprotectors are shown to propose a number of specific requirements (Shabanov P. D., 2009): 1) to have nootropic or nootropic-like effects consisting of an ability to improve the resistance of the organism, and the central nervous system in particular, to action of different damaged factors simultaneously with maintenance or enhancement of the higher functions of the brain; 2) to optimize metabolic activity of neural cells in action of aggressive factors of the environment; 3 ) to recover of impaired metabolism and energy deficit in neural cells; 4) to have anti-oxidative (anti-free radicals) effect; 5) to activate directly neurotrophic processes by means of stimulation of sprouting and formation of neurotrophic factors; 6 ) to prevent neuronal degeneration due to different pathological processes (autoimmune, toxic, aged, accelerated apoptosis). Among the candidates reviewed for these positions it should be consider cortexin, a peptide organ/tissue drug derived from the porcine brain cortex. The comparative investigation of a number peptide drugs (brain tissue drugs cerebrolysine and cortexin, synthetic peptides semax, selank, deltaran, noopept, dilept) in experimental and clinic conditions showed their high neuroprotective activity. It was registered both after administration of drugs into the brain ventriculi and after systemic (intraperitoneal) administration. The direction of effects after both types of administration was similar that indicated the peptide drugs penetrated the brain blood barrier. Moreover, the peptides were effective in diminution of subsequences following prolong social isolation, activation of the stress/antistress systems in early ontogeny (Shabanov P. D. et al., 2009), in experimental ischemia of the brain after occlusion of both carotid arteries, in traumatic toxicosis, after mechanic brain injury (Zarubina I. V. et al., 2011), in elevated seizure activity (Gulyaeva N.V. et al., 2011). In clinic, cortexin, cerebrolysine, semax and noopept were effective in postabstinent period in patients with alcoholism, in heavy somatic patients suffered from asthenic syndrome, in brain damaged patients, in children with seizure syndrome, after intoxication with neurotropic poisons, for acceleration of acclimatization in quick changes of meteorological conditions of environment (Ganapolskii V. P., 2011). It is important to emphasize that brain tissue drugs, cortexin in particular, were clinically more effective than synthetic neuropeptides, though in the experimental conditions their pharmacological activity often was higher than of brain tissue drugs. Besides, all drugs of metabolic type of action possessed an individual sensitivity to treatment when a half of patients reacted on drug brightly, but another one reacted by minimal improvement. Therefore, peptide neuroprotectors should be consider as perspective drugs for the treatment of many diseases of the central nervous system where both neuronal degeneration and reduction of metabolic status of the neural cells are the leading pathophysiological factors. 